\title{
Optical Properties of Al- and Zr-Doped Rutile Single Crystals Grown by Tilting-Mirror-Type Floating Zone Method and Study of Structure-Property Relationships by First Principle Calculations
}

\author{
Md. Abdur Razzaque Sarker ${ }^{1,2}$ \\ ${ }^{1}$ Center for Crystal Science and Technology, University of Yamanashi, 7-32 Miyamae, Kofu, Yamanashi 400-8511, Japan \\ ${ }^{2}$ Department of Physics, Rajshahi University, Rajshahi 6205, Bangladesh
}

Correspondence should be addressed to Md. Abdur Razzaque Sarker; razzaque_ru2000@yahoo.com

Received 25 May 2014; Accepted 12 July 2014; Published 17 August 2014

Academic Editor: Emmanuel Guillon

Copyright (C) 2014 Md. Abdur Razzaque Sarker. This is an open access article distributed under the Creative Commons Attribution License, which permits unrestricted use, distribution, and reproduction in any medium, provided the original work is properly cited.

\begin{abstract}
High quality and transparent single crystals of undoped rutile $\mathrm{TiO}_{2}, \mathrm{Al}$-doped rutile $\left(\mathrm{Al}: \mathrm{TiO}_{2}\right)$, and $\mathrm{Zr}$-doped rutile $\left(\mathrm{Zr}\right.$ : TiO$\left.{ }_{2}\right)$ have been grown successfully by tilting-mirror-type floating zone (TMFZ) using travelling solvent floating (TSFZ) technique. The effect of doping on the electronic and optical properties of rutile has been studied experimentally as well as by simulation calculations. The effect of doping on the quality of crystals was also investigated by observing optical micrograph and measuring etch pits density that reveals the presence of defects. Undoped rutile crystals were dark blue and comprised many low-angle grain boundaries. $\mathrm{Al}^{+3}$ and $\mathrm{Zr}^{+4}$ ions pin down the migration of dislocations during the cooling and create oxygen vacancies. Doping of the impurities would improve the electronic and optical properties of rutile. The elastic properties might be changed for doping of the impurities in the rutile crystals.
\end{abstract}

\section{Introduction}

Rutile $\left(\mathrm{TiO}_{2}\right)$ has excellent optical, mechanical, and chemical properties, and the demand for rutile single crystals has therefore been increasing to use as polarizer in a variety of optical devices because of their large refractive indices and birefringence [1]. It is of urgent necessity to grow rutile single crystals of high optical quality. The floating zone (FZ) method is one of the most promising techniques, which replace the Verneuil method, to grow rutile single crystals. Rutile single crystals were conventionally manufactured by the Verneuil method for gemstones [2]. However, the quality of Verneuil-grown crystals is usually poor, since the crystals undergo quenching, which induces stress birefringence [3]. The optical quality of the FZ-grown crystals was superior to that of commercially available Verneuil-grown rutile crystals [4]. Floating zone (FZ) method is a powerful technique for growth of single crystals without contaminations because it is a crucible free zone melting method. The segregation control of the dopant is very easy in this method by applying the travelling solvent floating zone technique. Hence, high quality single crystals with required dopant concentration are possible to grow by this technique from both congruently and incongruently melting compounds. The manufacturing use of the FZ method, however, is limited because the diameter of the crystals grown by this method is usually smaller than that by the other melt growth techniques such as the Czochralski, the Bridgman, and the Verneuil methods.

The shapes of both the melt-feed and the melt-crystal interfaces are convex in the FZ method and this convexity increases with increase in diameters of grown crystal and feed. This makes the instability of molten zone for the unexpected contacts between the feed rod and the grown crystal. The instability of the molten zone limits the diameter of the grown crystals in the conventional FZ method. It is reported that the interface shape can be controlled by tilting 


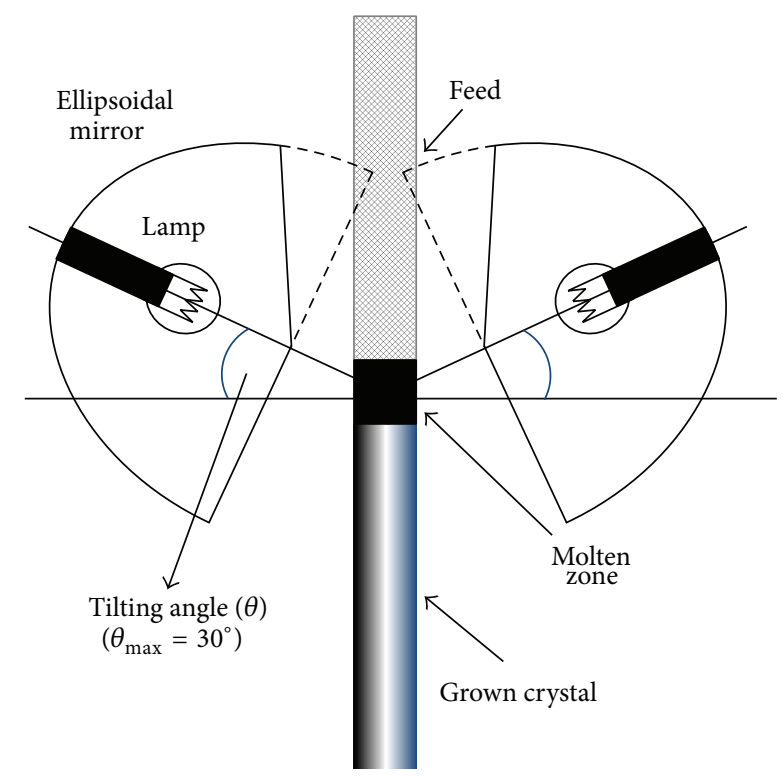

FIGURE 1: Schematic illustration of the tilting-mirror-type image furnace. The definition of tilting angle $(\theta)$ is given.

the mirror in the tilting-mirror-type floating zone (TMFZ) method as shown in Figure 1. The stability of the molten zone increases with increase in tilting angle that is favorable for growth of large diameter single crystals $[9,10]$. It was revealed that the quality of the TMFZ-grown crystals increases with increase in tilting angle [11] and growth diameter [10].

In this study, I try to grow high quality undoped and doped rutile single crystal by TMFZ method for optical device applications. The electrical and optical properties of this crystal are dominated by oxygen vacancies or incorporation of impurities without changing the crystallographic structure [12]. Many impurities have been added into rutile $\left(\mathrm{TiO}_{2}\right)$ to improve its electrical and optical properties depending on its applications. Higuchi and Kodaira reported that the number of low-angle grain boundaries in the FZgrown rutile was drastically reduced with the addition of $\mathrm{ZrO}_{2}$ or $\mathrm{Al}_{2} \mathrm{O}_{3}$ during growth [4]. They obtained that the grain boundary free rutile single crystals contain $1.0 \mathrm{~mol} \%$ $\mathrm{ZrO}_{2}$ and $\mathrm{Al}_{2} \mathrm{O}_{3}$ [13]. Here, we will investigate the effect of $\mathrm{Al}$ and $\mathrm{Zr}$ doping on the quality of rutile single crystals grown by the TMFZ method. I expect that the proper dopant affects the density of crystal defects such as etch pits, which indicate the presence of dislocations and low-angle grain boundaries.

The electronic and optical properties of $\mathrm{TiO}_{2}$ have been investigated experimentally using various methods. Nowadays, first principle $a b$ initio and density functionally theory (DFT) electronic structure calculations have been extensively used for interpretation of various properties of undoped and doped rutile. The defect structure varies with the oxygen vacancy concentration and metal impurities, which may alter electronic and optical properties of rutile and play an important role in technological applications of $\mathrm{TiO}_{2}$. Commercial $\mathrm{TiO}_{2}$ rutile pigments are always doped with $\mathrm{Al}_{2} \mathrm{O}_{3}$ to enhance photochemical stability. It is assumed that $\mathrm{Al}$ doping creates defects in the rutile lattice that act as traps for the photogenerated charges [8]. The addition of small quantity of $\mathrm{ZrO}_{2}$ was very effective to improve the quality of rutile crystals [4] although theoretical studies are rare.

In this study, I have successfully grown the undoped and doped $\left(\mathrm{Al}, \mathrm{Zr}\right.$ ) rutile $\mathrm{TiO}_{2}$ single crystals by infrared heating TMFZ method using travelling solvent floating zone technique. We also investigate the effects of aluminum and zirconium doping on optical and electronic properties of rutile experimentally as well as by first principle calculations.

\section{Experiment}

A new tilting-mirror-type image furnace (Crystal Systems Corporation, model TLFZ-4000-H-VPO) was developed for my growth experiment. The tilting angle $(\theta)$, as shown in Figure 1, can be changed to up to $30^{\circ}$ by a motor drive control. High-purity rutile powder $(>99.99 \%)$ was put into rubber tubes to form a rod shape and pressed at a pressure of up to $3.0 \times 10^{8} \mathrm{~Pa}$ using a cold isostatic pressing machine (Nikkiso Co., Ltd., model CL3-22-60). The rods were sintered at $1600^{\circ} \mathrm{C}$ for $12 \mathrm{~h}$ in an oxygen flow. The sintered rods were zonepassed in a $\mathrm{CO}_{2}$ flow at a growth rate of $25 \mathrm{~mm} / \mathrm{h}$ using a standard type four-mirror-type-image furnace (Crystal Systems Corporation, model FZ-4000H). The zone-passed feed rods were typically $10-12 \mathrm{~mm}$ in diameter and $80-$ $100 \mathrm{~mm}$ in length.

For solvent preparation, high purity $\mathrm{Al}_{2} \mathrm{O}_{3}$ (99.99\%) or $\mathrm{ZrO}_{2}(99.90 \%)$ was used with $\mathrm{TiO}_{2}$. Appropriate amounts of $\mathrm{TiO}_{2}$ and $\mathrm{Al}_{2} \mathrm{O}_{3}$ or $\mathrm{ZrO}_{2}$ were weighted out and mixed well. The concentration of $\mathrm{Al}$ or $\mathrm{Zr}$ in the solvent was 1.0 at $\%$. The applied conditions for every growth experiment were a growth rate of $5 \mathrm{~mm} / \mathrm{h}$, a feeding rate of $5 \mathrm{~mm} / \mathrm{h}$, upper shaft rotation of $3 \mathrm{rpm}$, lower shaft rotation of $50 \mathrm{rpm}$, a growth direction of $\langle 001\rangle$ using a rutile seed crystal, and an atmospheric-pressure oxygen flow. In case of undoped rutile, the growth atmosphere was $\mathrm{CO}_{2}$ flow because $\mathrm{CO}_{2}$ flow is used for the commercial production of the rutile crystals. The tilting angle $\theta$ was $20^{\circ}$. It was reported that this tilting condition was best for growth of good quality large diameter single crystals with the most stabilized molten zone. The grown crystals were cut perpendicular to the growth direction in the range $23-25 \mathrm{~mm}$ from the seeding point. Then the crystals were cut parallel to (110) and the surface was polished like mirror. The polished surfaces were observed by optical microscope (Olympus U-MSSPG Japan) to investigate the phase purity. The polished samples were soaked in a mixture of $\left(\mathrm{NH}_{4}\right)_{2} \mathrm{SO}_{4}$ and $\mathrm{H}_{2} \mathrm{SO}_{4}$ solutions $(1: 1$ weight ratio) for $3 \mathrm{~h}$ at $300^{\circ} \mathrm{C}$ to etch their surfaces. The polished samples of $\sim 1.5 \mathrm{~mm}$ in thickness were characterized by UV-Vis spectrometer (JASCO, V-660). The Agilent 4294A precision impedance analyzer was used for FTIR absorption spectrum.

\section{Computational Methods}

The calculations presented in this work were carried out by employing Cambridge serial total energy package (CASTEP) code [14] which utilizes the plane-wave pseudopotential 
TABLE 1: Comparison of calculated structural parameters $a, c$, and $u$, binding energy $E_{u}$, ground state energy $E_{0}$, bulk modulus $B_{0}$, shear modulus $G_{0}$, and band gap $E_{g}$ with experiment.

\begin{tabular}{lccccc}
\hline & Expt. & PWGGA & \multicolumn{3}{c}{ CASTEP [this work] } \\
& $\mathrm{TiO}_{2}$ & $\mathrm{TiO}_{2}$ & $\mathrm{TiO}_{2}$ & $\mathrm{Al}: \mathrm{TiO}_{2}$ & $\mathrm{Zr}: \mathrm{TiO}_{2}$ \\
\hline$a(\AA)$ & $4.59^{\mathrm{a}}$ & $4.63^{\mathrm{d}}$ & 4.64 & 4.64 & 4.65 \\
$c(\AA)$ & $2.96^{\mathrm{a}}$ & $2.98^{\mathrm{d}}$ & 2.96 & 2.98 & 2.97 \\
$u$ & 0.305 & $0.305^{\mathrm{d}}$ & 0.305 & 0.305 & 0.305 \\
$E_{u}(\mathrm{~kJ} / \mathrm{mol})$. & $-1915^{\mathrm{a}}$ & $-2054^{\mathrm{d}}$ & -2048 & -2022 & -2042 \\
$E_{0}(\mathrm{eV})$ & $\ldots$ & $\ldots$ & -4963 & -4937 & -4956 \\
$B_{0}(\mathrm{GPa})$ & $216^{\mathrm{b}}$ & $223^{\mathrm{d}}$ & 201 & 204 & 214 \\
$G_{0}(\mathrm{GPa})$ & $\ldots$ & $\ldots$ & 123 & 118 & 123 \\
$E_{g}(\mathrm{eV})$ & $3.03^{\mathrm{c}}$ & $1.90^{\mathrm{d}}$ & 1.88 & 1.94 & 1.85 \\
\hline
\end{tabular}

${ }^{\mathrm{a}}$ Reference [5].

${ }^{\mathrm{b}}$ Reference [6].

${ }^{c}$ Reference [7].

${ }^{\mathrm{d}}$ Reference [8].

based on the framework of density functional theory (DFT) method. The electronic exchange-correlation energy is treated under the generalized gradient approximation (GGA) in the scheme of Perdew-Bruke-Ernzerhof [15]. The interactions between the ions and electron are represented by ultrasoft Vanderbilt-type pseudopotentials for $\mathrm{Ti}, \mathrm{Al}, \mathrm{Zr}$, and $\mathrm{O}$ atoms [16]. The basis set of valence electronic states was set to be $3 d^{2} 4 s^{2}$ for $\mathrm{Ti}, 3 \mathrm{~s}^{2} 3 \mathrm{p}^{1}$ for $\mathrm{Al}, 4 \mathrm{~d}^{2} 5 \mathrm{~s}^{2}$ for $\mathrm{Zr}$, and $2 s^{2} 2 p^{4}$ for $O$. The calculations use plane-wave cut-off energy of $1100 \mathrm{eV}$ for all cases. For sampling of the Brillouin zone, a Monkhorst-Pack grid [17] of $7 \times 7 \times 11 \mathrm{k}$-points was employed for all calculations. All the structures were relaxed by Broyden-Fletcher-Goldfarb-Shenno (BFGS) methods [18]. For the geometry optimization, the convergence tolerances were set as follows: $5 \times 10^{-6} \mathrm{eV} /$ atom for the total energy, $0.001 \mathrm{eV} / \AA$ for the maximum force on atoms, $0.02 \mathrm{GPa}$ for the maximum stress, and $5 \times 10^{-4} \AA$ for the maximum atomic displacement. The total energy is conversed to within $0.01 \mathrm{~m} \mathrm{Ry/unit}$ cell during the self-consistency cycle.

\section{Results and Discussions}

4.1. Bulk Properties of Rutile. The single crystals of pure $\mathrm{Al}$-doped and $\mathrm{Zr}$-doped rutile $\mathrm{TiO}_{2}$ were stably grown by infrared heating tilting-mirror-type floating zone (TMFZ) method using travelling solvent floating zone (TSFZ) technique. Figure 2 shows the photographs of conventional FZ grown undoped rutile crystals and TMFZ grown undoped rutile, Al-doped rutile and Zr-doped rutile crystals. From the view of the grown crystals, TMFZ grown crystals look nice in comparison to FZ grown crystals. The transparency of the FZ grown crystal along growth direction is not homogeneous and seems to be some inclusions inside. Figure 2 shows that the FZ grown undoped rutile $\mathrm{TiO}_{2}$ crystal is blue and TMFZ grown undoped rutile $\mathrm{TiO}_{2}$ crystal is dark blue; on the other hand, Al-doped rutile crystal is pale-yellow and $\mathrm{Zr}$ doped rutile crystal is light blue color. The color of undoped and $\mathrm{Zr}$-doped rutile is uniform along the growth directions.
However, the color of Al-doped rutile crystal is slightly changed along the growth direction. This means that the segregation of $\mathrm{Zr}$ is uniform and that of $\mathrm{Al}$ is slightly changed during TSFZ growth. It was revealed that maximum solubility of $\mathrm{Al}$ and $\mathrm{Zr}$ in rutile is 1 at \% because it was difficult to maintain the molten zone as stable for solvent of more than 1 at $\% \mathrm{Al}$ or $\mathrm{Zr}$ dopant.

4.2. Structural and Electronic Properties. The BFGS algorithm is used to perform geometry optimization for tetragonal rutile $\mathrm{TiO}_{2}$ at experimental lattice constant of $a=b=4.594 \AA$ and $c=2.958 \AA$ [5]. The equilibrium lattice parameters and elastic constants are calculated at the optimized structure that contains the lattice constants of $a=b=4.642 \AA$ and $c=$ $2.965 \AA$. The optimized structure parameters, $a, c$, and $u$, the cohesive energy per $\mathrm{TiO}_{2}$ unit $E_{u}$, the ground state energy $E_{0}$, the bulk modulus $B_{0}$, the shear modulus $G_{0}$, and the band gap $E_{g}$ obtained with Perdew-Wang exchange-correlation functional PWGGA [8] and plane-wave pseudopotential DFT based CASTEP are given in Table 1 together with the corresponding experimental values $[6,7,19]$. The calculated structural parameters obtained with theoretical calculations are close to the experimental values. The value of $a$ increases by $0.21 \%$ for 1 at $\% \mathrm{Zr}$ doping in $\mathrm{Ti}$ site. The values of $c$ increase by $0.34 \%$ for 1 at $\% \mathrm{Zr}$ doping and by $0.68 \%$ for 1 at $\% \mathrm{Al}$ doping in Ti site. The calculated values of $E_{u}$ obtained with theories are in good agreement with experimental value $(-1915 \mathrm{~kJ} / \mathrm{mole})$. The largest deviation, $7.26 \%$, is obtained from the PWGGA calculations. The values of ground state energy, $E_{0}$, increase by $7 \mathrm{eV}$ for 1 at $\% \mathrm{Zr}$ doping and by $26 \mathrm{eV}$ for 1 at $\% \mathrm{Al}$ doping in $\mathrm{Ti}$ site.

The calculated value of bulk modulus for undoped rutile $\mathrm{TiO}_{2}$ is $201 \mathrm{GPa}$, for $\mathrm{Al}: \mathrm{TiO}_{2}$ is $204 \mathrm{GPa}$, and for $\mathrm{Zr}: \mathrm{TiO}_{2}$ is $214 \mathrm{GPa}$ which is in good agreement with experimental value of $216 \mathrm{GPa}$ [7]. The shear modulus of pure rutile $\mathrm{TiO}_{2}$ and $\mathrm{Zr}: \mathrm{TiO}_{2}$ is $123 \mathrm{GPa}$, whereas that of $\mathrm{Al}: \mathrm{TiO}_{2}$ is $118 \mathrm{GPa}$. It is well known that a material is being ductile or brittle depending on the ratio of shear modulus and bulk modulus $\left(G_{0} / B_{0}\right)$. If $G_{0} / B_{0}>0.5$, the material is ductile; if $G_{0} / B_{0}<$ 0.5 , the material is brittle. Here, all three samples are ductile and the ductility decreases slightly for $\mathrm{Al}$ or $\mathrm{Zr}$ doping. The ductility is one of the important properties of rutile in the device applications.

Rutile is a semiconductor with a band gap $\left(E_{g}\right)$ of $3.03 \mathrm{eV}$ [19]. In the present study, the band structure was computed along the direction that contains the highest number of symmetry points within the Brillouin zone, namely, $\Gamma-\mathrm{X}-$ $\mathrm{R}-\mathrm{Z}-\mathrm{\Gamma}-\mathrm{M}-\mathrm{A}-\mathrm{Z}$. The calculated band structures of the pure rutile $\mathrm{TiO}_{2}, \mathrm{Al}: \mathrm{TiO}_{2}$, and $\mathrm{Zr}: \mathrm{TiO}_{2}$ are presented in Figure 3 . Here, the top of the valence band is chosen to be the Fermi level $\left(E_{f}=0 \mathrm{eV}\right)$. The valence band maximum and conduction band minimum occur at $\Gamma$ point, making this material a direct band gap material $(\Gamma-\Gamma)$. The calculated $E_{g}$ values are given in Table 1 . The calculated band gaps of the pure rutile $\mathrm{TiO}_{2}, \mathrm{Al}: \mathrm{TiO}_{2}$, and $\mathrm{Zr}: \mathrm{TiO}_{2}$ are $1.88 \mathrm{eV}, 1.94 \mathrm{eV}$, and $1.85 \mathrm{eV}$ that are the same with band gap value of other theoretical calculations $[8,20,21]$. The $\Gamma$ point conduction band minimum in rutile is almost degenerate with minima $\mathrm{M}$ 


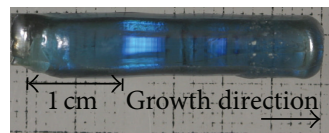

(a)

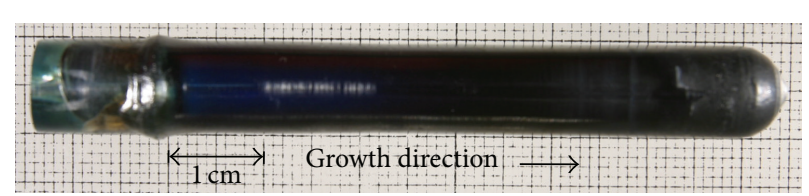

(b)

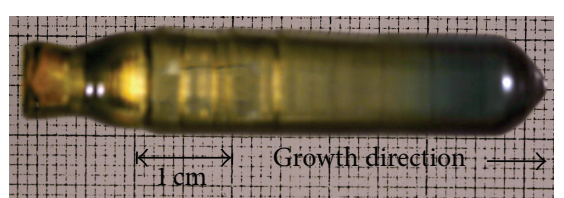

(c)

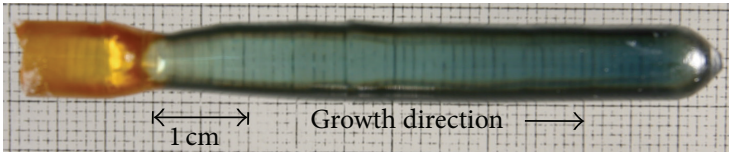

(d)

FIgure 2: Photographs of the crystals of (a) pure rutile $\mathrm{TiO}_{2}$ grown by $\mathrm{FZ}$ method and (b) pure rutile $\mathrm{TiO}_{2}$, (c) $\mathrm{Al}: \mathrm{TiO}_{2}$, and (d) $\mathrm{Zr}$ : TiO 2 grown by TMFZ method.

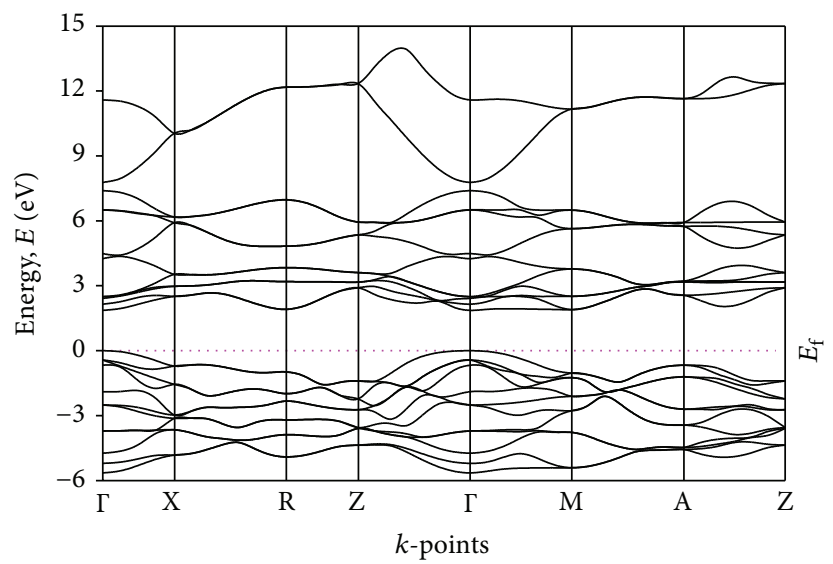

(a)

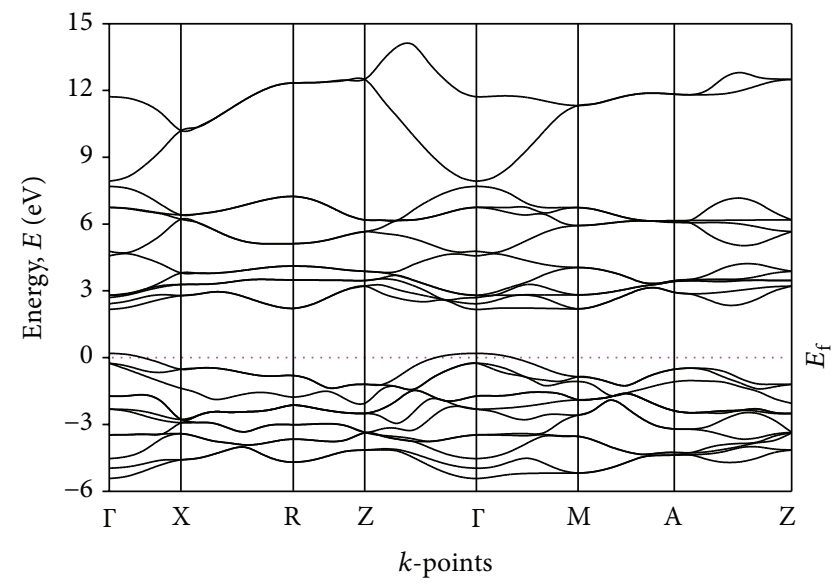

(b)

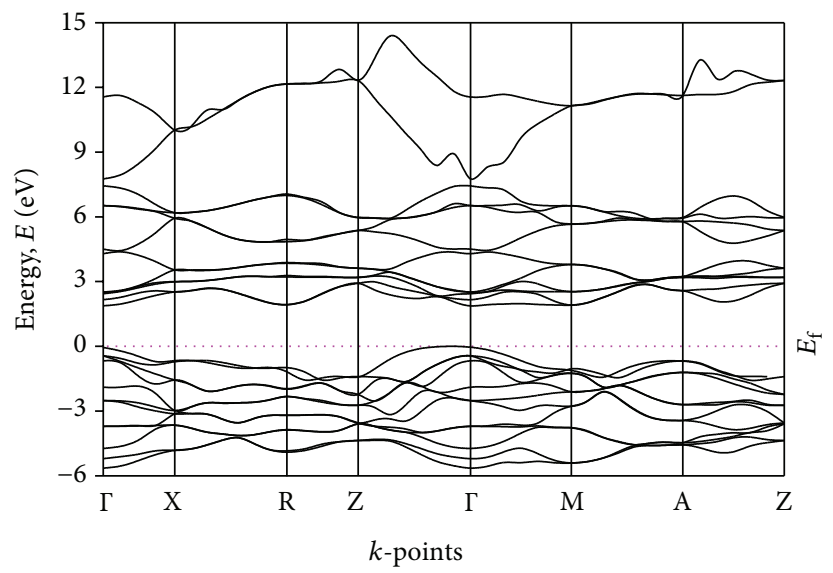

(c)

FIgure 3: Band structure of (a) pure rutile $\mathrm{TiO}_{2}$, (b) $\mathrm{Al}: \mathrm{TiO}_{2}$, and (c) $\mathrm{Zr}$ : $\mathrm{TiO}_{2}$. The $E_{f}$ represents the Fermi level.

and $\mathrm{R}$. The band gap slightly narrowed $(0.03 \mathrm{eV})$ for $\mathrm{Zr}$ doping and increased $(0.06 \mathrm{eV})$ for $\mathrm{Al}$ doping in pure rutile $\mathrm{TiO}_{2}$. The valence bands and conduction bands are clearly split up at Z$\Gamma-\mathrm{M}$ path. It is observed that there are some impurity bands in case of $\mathrm{Al}: \mathrm{TiO}_{2}$ and $\mathrm{Zr}: \mathrm{TiO}_{2}$.

Some important features of the band gaps are presented in Table 2. The minimal vertical transition (MVT) and minimal indirect transition (MIT) energies are given in this table. The MVT is along $\Gamma-\Gamma$ direction. Experimental investigations using absorption and photoluminescence spectroscopy [7] and wavelength modulated transmission spectroscopy [22] have also determined that rutile is a direct forbidden gap semiconductor. In agreement with some theoretical investigations $[23,24]$, our calculations also predict that rutile has 
TABLE 2: Comparison of direct and indirect band gaps energies $(\mathrm{eV})$ and symmetry of the valance to conduction band transition for rutile $\mathrm{TiO}_{2}$, Al-doped rutile, and $\mathrm{Zr}$-doped rutile.

\begin{tabular}{lccc}
\hline $\begin{array}{l}\text { Valance to conduction } \\
\text { band transition }\end{array}$ & \multicolumn{3}{c}{ Band gap energies (eV) } \\
\hline$\Gamma-\Gamma$ & 1.8805 & 1.9411 & 1.8529 \\
$\Gamma-\mathrm{Z}$ & 2.8656 & 3.0882 & 2.9117 \\
$\Gamma-\mathrm{R}$ & 1.9701 & 2.1176 & 1.9411 \\
$\Gamma-\mathrm{M}$ & 1.9701 & 2.1176 & 1.9411 \\
$\mathrm{X}-\mathrm{X}$ & 3.2238 & 3.3529 & 3.1764 \\
$\mathrm{R}-\mathrm{R}$ & 2.8656 & 3.0882 & 2.9117 \\
$\mathrm{Z}-\mathrm{Z}$ & 4.2985 & 4.4117 & 4.4117 \\
$\mathrm{M}-\mathrm{M}$ & 2.8546 & 3.0882 & 2.9117 \\
$\mathrm{~A}-\mathrm{A}$ & 3.2238 & 3.3529 & 3.2647 \\
\hline
\end{tabular}

the smallest indirect gap along the $\Gamma-\mathrm{M}$ or $\Gamma-\mathrm{R}$ direction. The MIT energy along $\Gamma-\mathrm{M}$ or $\Gamma-\mathrm{R}$ is $1.97 \mathrm{eV}$ which is very close to the MVT energy $(1.88 \mathrm{eV})$. The second MVT is along $\mathrm{M}-\mathrm{M}$ with energy of $2.85 \mathrm{eV}$ and the second MIT is along $\Gamma-Z$ with energy of $2.86 \mathrm{eV}$ which are also very close.

In order to get more physical insight of the electronic band structure, we calculated the total density of states (TDOS) and partial density of states (PDOS) of pure rutile $\mathrm{TiO}_{2}, \mathrm{Al}: \mathrm{TiO}_{2}$, and $\mathrm{Zr}: \mathrm{TiO}_{2}$. A comparison of TDOS is shown in Figure 4(a). The TDOS is extended from about $-5.92 \mathrm{eV}$ to $7.78 \mathrm{eV}$ where the Fermi-level position is set to $0 \mathrm{eV}$. Figure 4(a) shows that TDOS of $\mathrm{Zr}: \mathrm{TiO}_{2}$ shifted slightly and that of $\mathrm{Al}: \mathrm{TiO}_{2}$ shifted effectively from TDOS of $\mathrm{TiO}_{2}$. The density of states at the Fermi level is 0.441, 0.664, and 0.446 states/eV for pure rutile $\mathrm{TiO}_{2}, \mathrm{Al}: \mathrm{TiO}_{2}$, and $\mathrm{Zr}: \mathrm{TiO}_{2}$, respectively. Every DOS value at Fermi level reveals that rutile is a perfect semiconductor.

Figure 4(b) shows that the valance band (VB) and conduction band (CB) are composed of both Ti $3 d$ and $\mathrm{O} 2 p$ orbitals. The VB is mainly composed of $\mathrm{O} 2 p$ states with some hybridization with $\mathrm{Ti} 3 d$ orbitals and the top of the valence band is dominated by $\mathrm{O} 2 p$ states. On the other hand, the conduction band has Ti $3 d$ states with weak hybridization of O $2 p$ states; and Ti $3 d$ states are dominant here over $\mathrm{O} 2 p$ states. It reveals that the transition between $\mathrm{VB}$ and $\mathrm{CB}$ is due to the $\mathrm{O} 2 p$ and $\mathrm{Ti} 3 d$ states, because these states have maximum contribution to $\mathrm{VB}$ and $\mathrm{CB}$. The valance-band width of $6.29 \mathrm{eV}$ is in good agreement with experimental results $[25,26]$. On the other hand, the conduction bands have a width of $5.92 \mathrm{eV}$. The two peaks in the conduction band are a result of the ligand field splitting of the $\mathrm{Ti} 3 d$ orbitals into two sets, $t_{2 g}$ and $e_{g}$ orbitals, where $e_{g}$ orbitals are associated with upper conduction band [27]. The $t_{2 g}$ and $e_{g}$ states represent the $\pi$ and $\sigma$ Ti $3 d$ orbitals hybridized with $\mathrm{O}$ $2 p$ states. Figure $4(\mathrm{c})$ shows the partial DOS of $\mathrm{Al}: \mathrm{TiO}_{2}$ and 4(d) shows that of $\mathrm{Zr}: \mathrm{TiO}_{2}$. In the $\mathrm{Al}: \mathrm{TiO}_{2}$, the contribution of $\mathrm{Al} 3 p$ is larger in the valance band than in the conduction band and the contribution of $\mathrm{Al} 2 s$ is insignificant. In the $\mathrm{Zr}: \mathrm{TiO}_{2}$, contribution of $\mathrm{Zr} 4 p$ is significant in the valance band and that of $\mathrm{Zr} 4 d$ is significant in the conduction band.

Figure 5 show the optical micrographs of conventional IR-FZ grown undoped $\mathrm{TiO}_{2}$ crystal and TMFZ grown undoped $\mathrm{TiO}_{2}, \mathrm{Al}: \mathrm{TiO}_{2}$ and $\mathrm{Zr}: \mathrm{TiO}_{2}$ crystals, respectively. The samples were polished mechanically like mirror on (110) surface and observed by optical microscopy. In a recent work, we showed that growth of large diameter single crystal is possible by TMFZ method [10] and quality of the grown crystals improved here [11]. In this work, I tried to compare the quality of the single crystals grown by the conventional FZ and TMFZ methods. In Figure 5(a), there are some grain boundaries in the FZ grown crystals, while Figures 5(b)-5(a) show no grain boundaries or secondary phases. Although little impurity spots were observed in Figure 5(b) for undoped rutile crystals, Figures 5(c) and 5(d) show that $\mathrm{Al}: \mathrm{TiO}_{2}$ and $\mathrm{Zr}: \mathrm{TiO}_{2}$ crystals grown by TMFZ method were almost defect-free. These results reveal that TMFZ is a powerful method for growth of high quality single crystals. To investigate the quality of the grown crystals in more details, I analyze the defects by measuring etch pits density (EPD). Figure 6 shows optical microphotographs of the samples on (110) surface after chemical etching. The observed etch pits are clearly more in the crystal grown by conventional FZ method compared with that in the crystal grown by TMFZ method as shown in Figures 6(a) and 6(b), respectively. The EPD in the crystals grown by conventional FZ method is $3.313 \times 10^{4} \mathrm{~cm}^{-2}$ and that in the crystals grown by the $\operatorname{TMFZ}\left(\theta=20^{\circ}\right)$ method is $1.157 \times 10^{4} \mathrm{~cm}^{-2}$. So EPD was reduced by $50 \%$ with TMFZ growth. The EPDs also reduced for doping effects. The TMFZ $\left(\theta=20^{\circ}\right)$ grown $\mathrm{Al}: \mathrm{TiO}_{2}$ and $\mathrm{Zr}: \mathrm{TiO}_{2}$ have EPDs as $0.57 \times$ $10^{4} \mathrm{~cm}^{-2}$ as shown in Figures 6(c)-6(d), that is, 50\% less compared to the EPDs in undoped $\mathrm{TiO}_{2}$ as shown in Figure 6(b). As the etch pits are associated with dislocations [28] and grain boundaries [29], the quality of the rutile crystals can be improved by tilting the mirror in TMFZ method as well as by doping the proper dopants. Hence, the doping of suitable foreign particles is effective to decrease the defects such as dislocations and low-angle grain boundaries in the rutile crystals.

The ac conductance of the samples was measured by impedance analyzer, where the signal frequency was varied from $100 \mathrm{~Hz}$ to $10 \mathrm{M} \mathrm{Hz}$ and oscillating voltage $300 \mathrm{mV}$ was applied. Figure 7(a) shows the frequency dependence ac conductance of doped and undoped $\mathrm{TiO}_{2}$ samples where the ac conductance increased with frequency up to $5 \mathrm{MHz}$ and then decreased. The ac conductance is higher in undoped $\mathrm{TiO}_{2}$ sample than $\mathrm{Al}: \mathrm{TiO}_{2}$ and $\mathrm{Zr}: \mathrm{TiO}_{2}$ samples. Hatta et al. reported that the conductivity of $\mathrm{Al}: \mathrm{TiO}_{2}$ crystal was larger by one order of magnitude than that of the pure crystal, which indicates that the diffusion rate of oxygen ions is much higher in the $\mathrm{Al}: \mathrm{TiO}_{2}$ crystal than in the pure crystal [30]. In this work, it is shown that the frequency response ac conductance strongly depends on the doping effects of rutile. The impedance was also measured at frequency range of $100 \mathrm{~Hz}$ to $10 \mathrm{MHz}$ by impedance analyzer. Figure 7(b) shows 

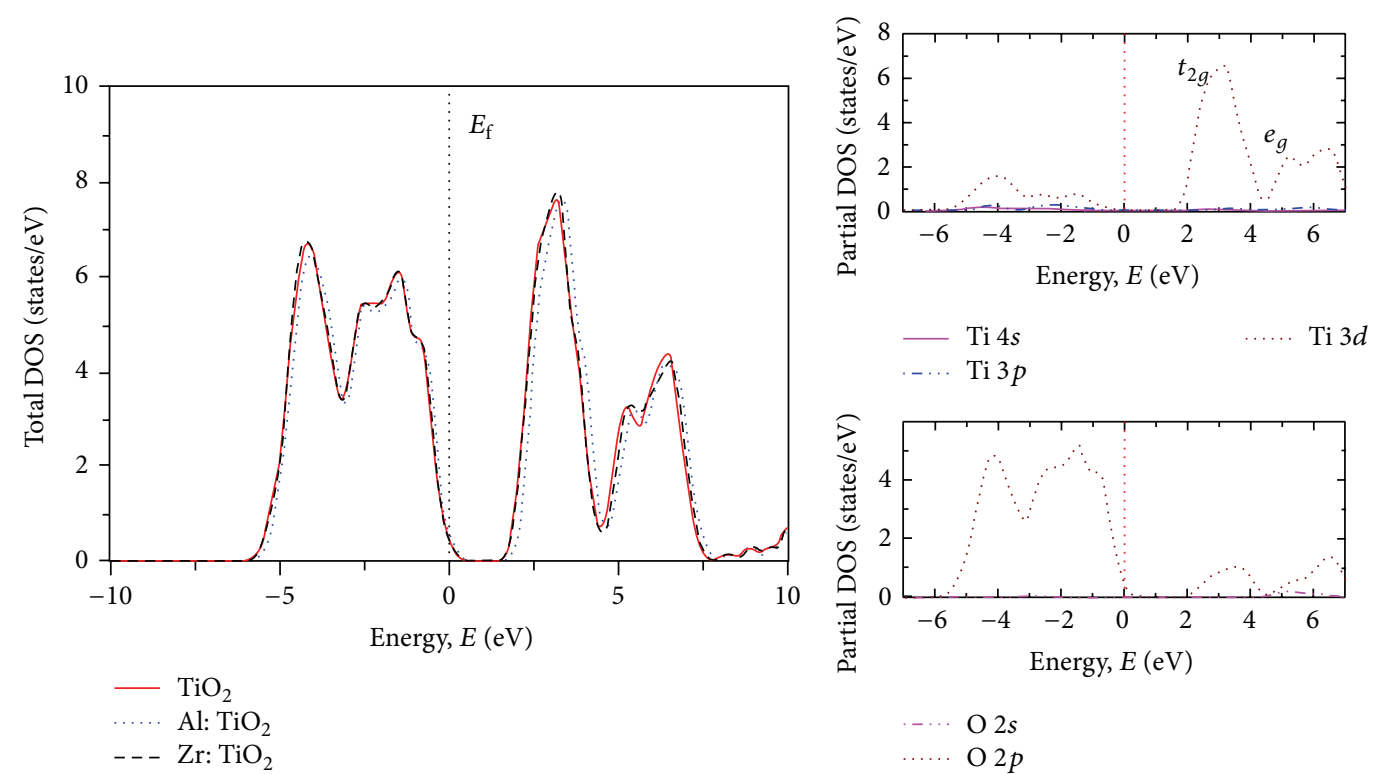

(a)

(b)
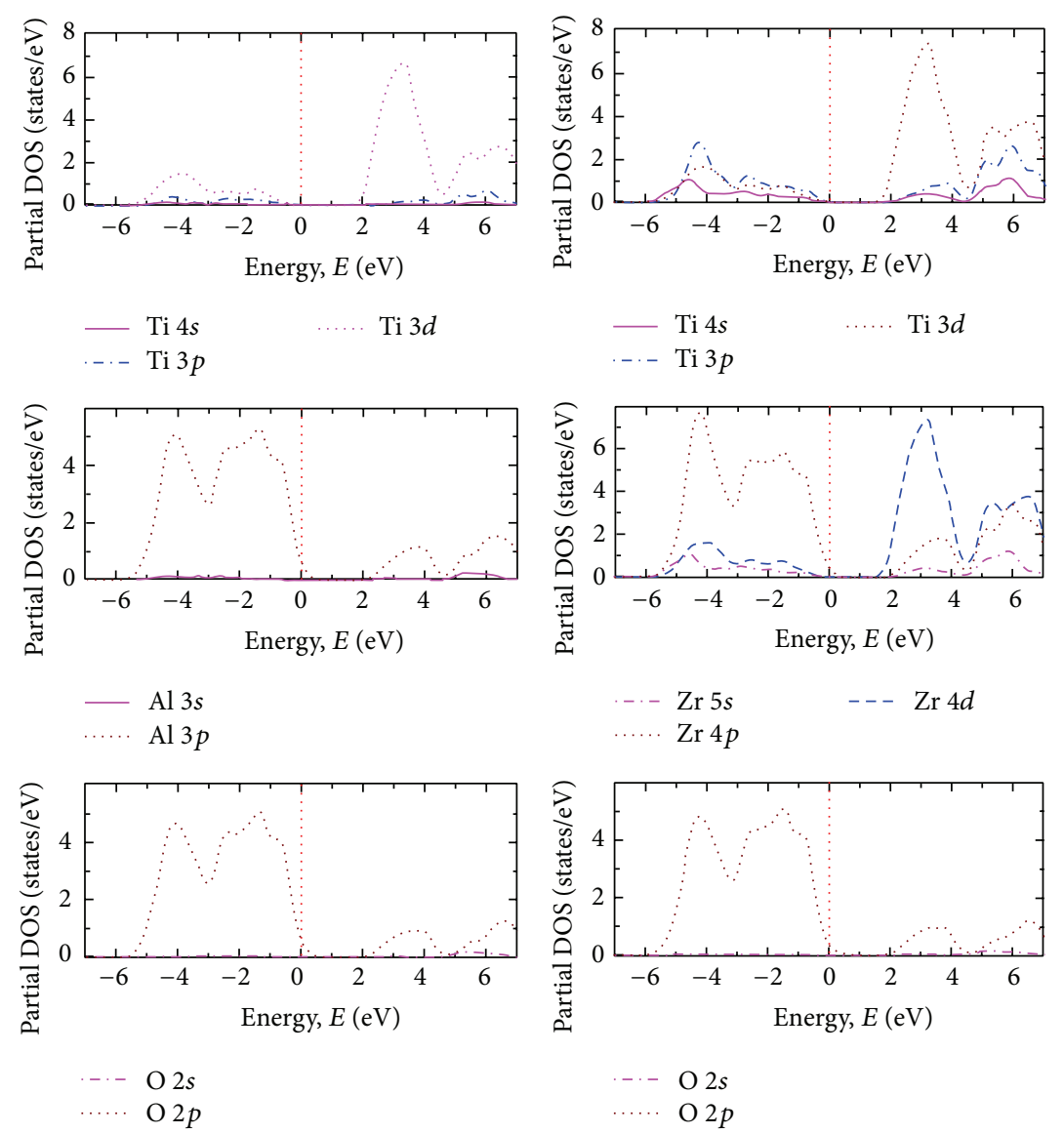

(c)

(d)

FIgure 4: (a) Total DOS of the pure and doped rutile. Partial DOS of (b) pure rutile $\mathrm{TiO}_{2}$, (c) $\mathrm{Al}: \mathrm{TiO}_{2}$, and (d) $\mathrm{Zr}$ : $\mathrm{TiO}_{2}$ crystals. 


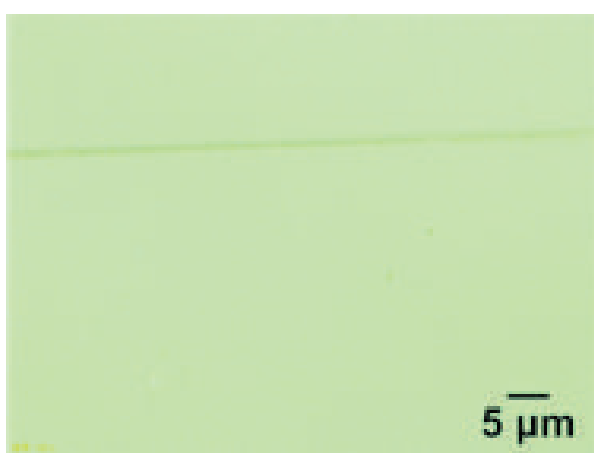

(a)

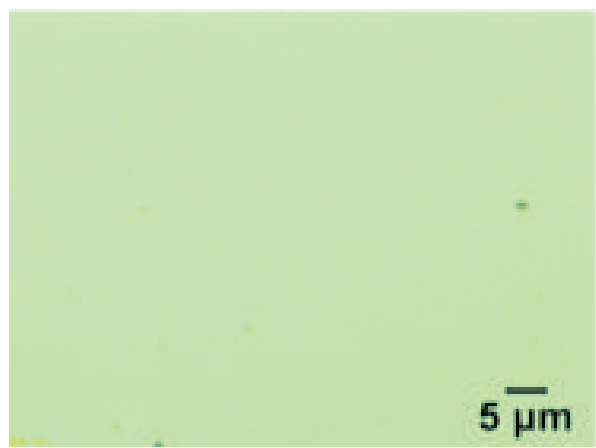

(c)

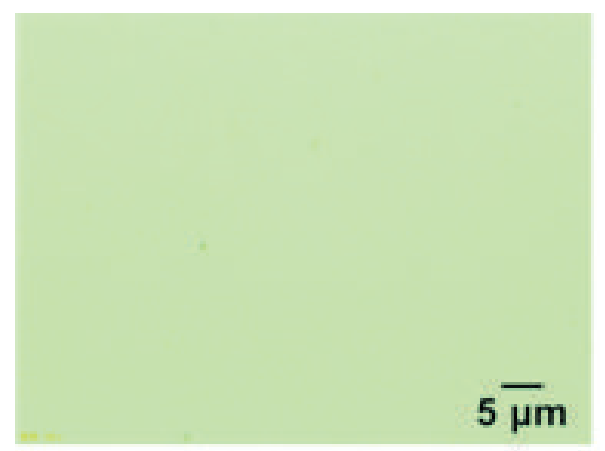

(b)

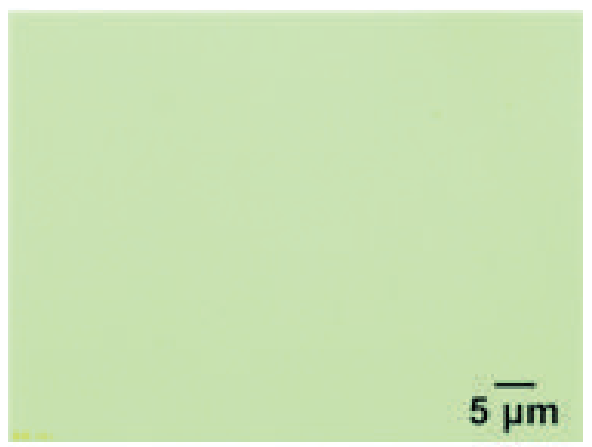

(d)

FIGURE 5: Optical micrographs of polished cross-section of (a) undoped rutile crystal by IR-FZ method and (b) undoped $\mathrm{TiO}_{2}$, (c) $\mathrm{Al}$ : $\mathrm{TiO}_{2}$, and(d) $\mathrm{Zr}: \mathrm{TiO}_{2}$ crystals by TMFZ method.

the frequency dependence impedance of doped and undoped $\mathrm{TiO}_{2}$ samples. The ac conductance is lower in undoped $\mathrm{TiO}_{2}$ sample than in $\mathrm{Al}: \mathrm{TiO}_{2}$ and $\mathrm{Zr}: \mathrm{TiO}_{2}$ samples.

As the impedance is opposite to ac conductance, the impedance also strongly depends on the doping effects of rutile.

4.3. Optical Properties of Rutile. Dielectric properties of the doped and undoped rutile $\mathrm{TiO}_{2}$ samples were studied by precision impedance analyzer. Silver paste was coated on both surfaces of each sample before measurement. Dielectric constant is a measure of materials ability to store electric charge. The frequency dependence capacitance of samples was measured within the frequency range of $100 \mathrm{~Hz}$ to $10 \mathrm{MHz}$ at room temperature as shown in Figure 8(a). The capacitance of all samples is high at low frequency region and decreases with increase in frequency. The capacitance is higher in undoped $\mathrm{TiO}_{2}$ sample than in $\mathrm{Al}: \mathrm{TiO}_{2}$ and $\mathrm{Zr}$ : $\mathrm{TiO}_{2}$ samples. Figure 8(b) shows the frequency dependence dielectric constant of the doped and undoped rutile $\mathrm{TiO}_{2}$ samples. The capacitance of the samples is high at low frequency region due to contribution of all kinds of polarization at low frequency and then decreases with increase in frequency. This is due to the change of space charge and ionic and orientation polarization at higher frequencies [31]. The dielectric constant is higher in undoped $\mathrm{TiO}_{2}$ sample than in $\mathrm{Al}: \mathrm{TiO}_{2}$ and $\mathrm{Zr}: \mathrm{TiO}_{2}$ samples. Frequency response capacitance and dielectric constant strongly depend on the doping effects on the $\mathrm{TiO}_{2}$ rutile crystals.

The transmittance data of the disc-like samples with $1.5 \mathrm{~mm}$ in thickness is shown in Figure 9. The intensity increased for the doping effect of $\mathrm{Al}$ and $\mathrm{Zr}$ on the pure rutile $\mathrm{TiO}_{2}$. This result is consistent with the color change of grown crystals as shown in Figure 2. This change corresponds to the change of oxygen deficiencies. The band edge is $420 \mathrm{~nm}$ for all samples, which is independent of the $\mathrm{Al}$ or $\mathrm{Zr}$ dopant. Although impurity bands are observed in band structure of $\mathrm{Al}: \mathrm{TiO}_{2}$ and $\mathrm{Zr}$ : $\mathrm{TiO}_{2}$ as shown in Figures 3(b) and 3(c), it was insignificant and cannot influence the band edge. The transmission peak of pure rutile $\mathrm{TiO}_{2}$ is at $468 \mathrm{~nm}$ and that of $\mathrm{Zr}: \mathrm{TiO}_{2}$ is at $549 \mathrm{~nm}$, but the peak is wide. However, the transmission peak of $\mathrm{Al}: \mathrm{TiO}_{2}$ is at $850 \mathrm{~nm}$ which is out of the visible region.

Figure 10 shows the Fourier transform infrared (FTIR) absorption spectra of pure and aluminum doped rutile powder samples. It shows that the spectra for pure rutile and $\mathrm{Al}: \mathrm{TiO}_{2}$ are not identical because the dopant influences the chemical bonding and bond length and structure. At $499 \mathrm{~cm}^{-1}$ of $\mathrm{TiO}_{2}$ absorption spectrum, there is a sharp peak, but at $704 \mathrm{~cm}^{-1}$, there is a broad peak due to the formation of $\mathrm{Ti}-\mathrm{O}$ bonds. At $\sim 664 \mathrm{~cm}^{-1}$ of Al: $\mathrm{TiO}_{2}$ absorption spectrum, there is a broad peak due to formation of Ti-O bonds as well as $\mathrm{Al}-\mathrm{O}$ bonds since $\mathrm{Al}$ was doped in the Ti site. $\mathrm{TiO}_{2}$ sample 


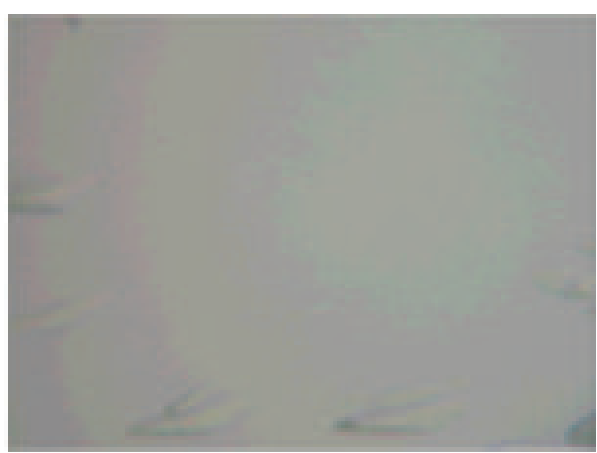

(a)

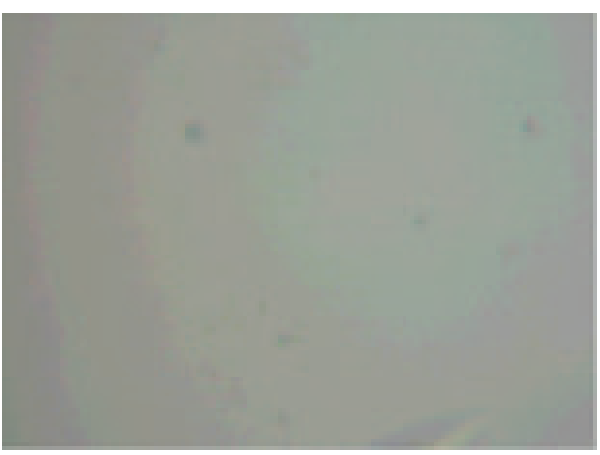

(c)

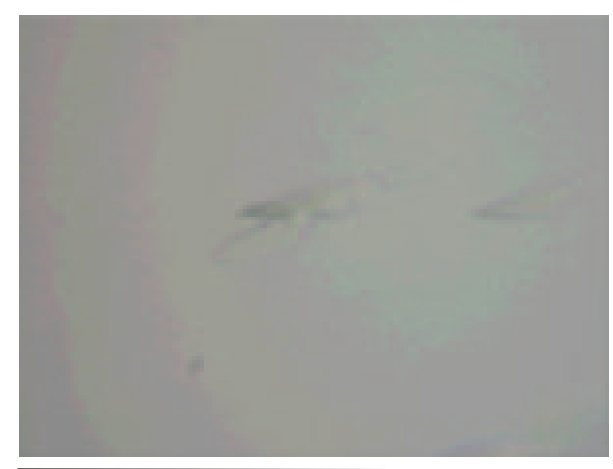

$100 \mu \mathrm{m}$

(b)

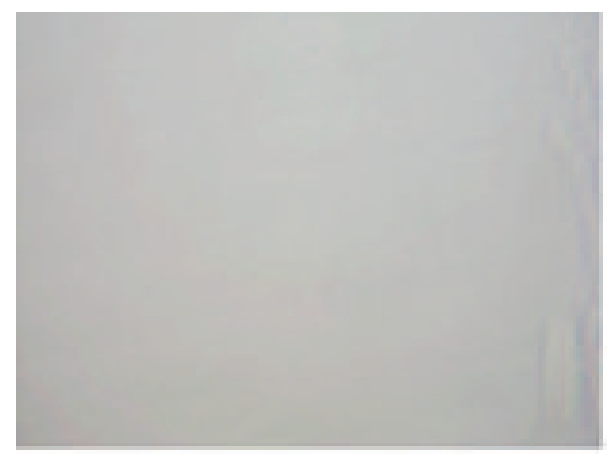

(d)

FIGURE 6: Optical microphotographs of etch pits on (100) of rutile single crystals grown by (a) conventional FZ method, (b) TMFZ method, (c) $\mathrm{Al}: \mathrm{TiO}_{2}$, and (d) $\mathrm{Zr}: \mathrm{TiO}_{2}$.

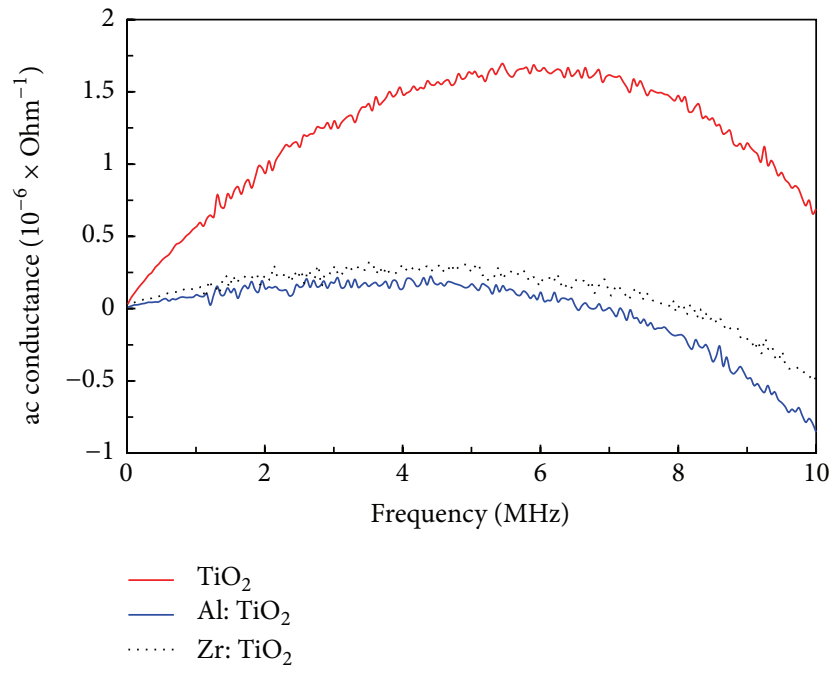

(a)

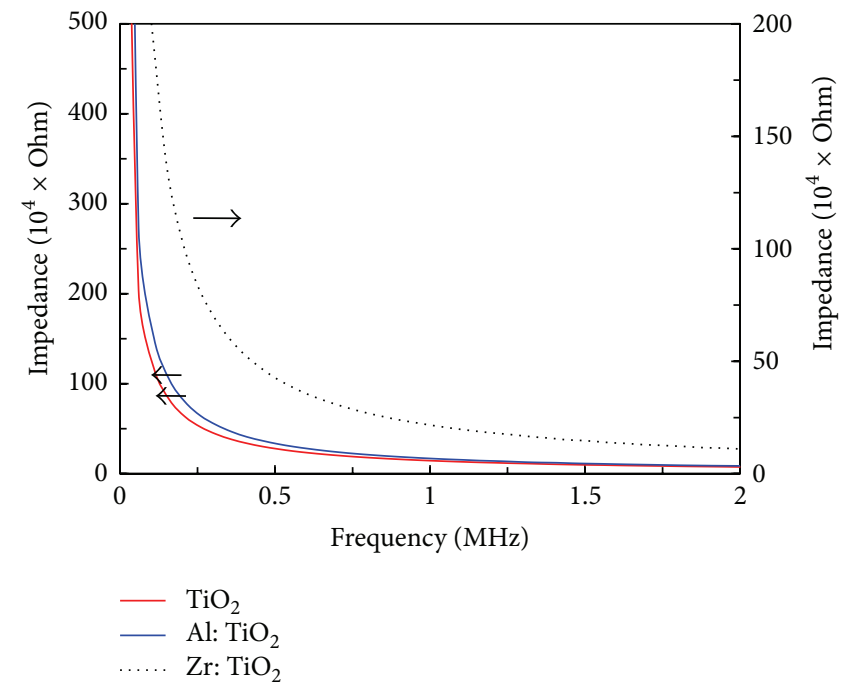

(b)

FIgURE 7: The frequency dependence of electrical conductance and impedance of undoped and doped rutile $\mathrm{TiO}_{2}$.

shows that there are three sharp medium absorption peaks at $1084 \mathrm{~cm}^{-1}, 1124 \mathrm{~cm}^{-1}$, and $1197 \mathrm{~cm}^{-1}$ which are all due to the vibrations of the rutile crystal lattice. The $\mathrm{Al}: \mathrm{TiO}_{2}$ sample shows that there is a broad weak absorption peak at $1125 \mathrm{~cm}^{-1}$. Two medium peaks for both samples overlap at $1650 \mathrm{~cm}^{-1}$.
There is a sharp strong peak at $3448 \mathrm{~cm}^{-1}$ for $\mathrm{TiO}_{2}$ sample and broad strong peak at $3479 \mathrm{~cm}^{-1}$ for $\mathrm{Al}: \mathrm{TiO}_{2}$ sample; both absorption peaks are due to $\mathrm{O}-\mathrm{O}$ bonds. The average absorption intensity of $\mathrm{TiO}_{2}$ sample is higher than that of $\mathrm{Al}: \mathrm{TiO}_{2}$. 


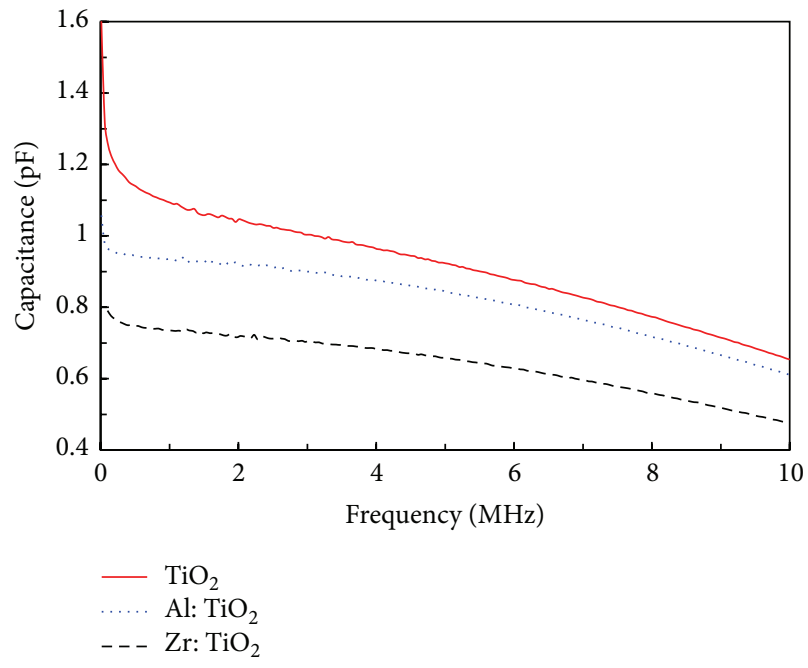

(a)

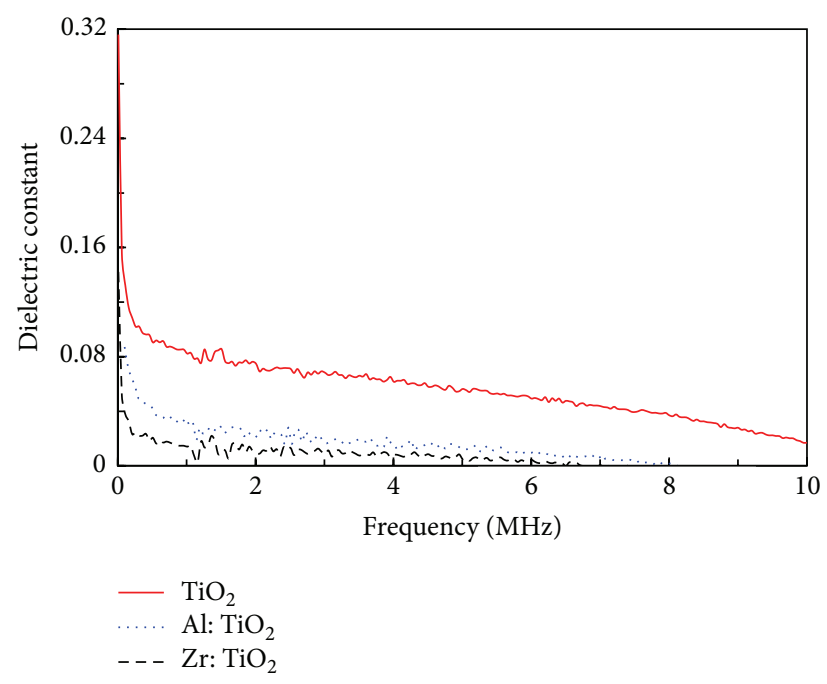

(b)

FIGURE 8: The frequency dependence of capacitance and dielectric constant of undoped and doped rutile $\mathrm{TiO}_{2}$.



FIGURE 9: Transmittance as a function of wavelength of light for undoped and doped rutile $\mathrm{TiO}_{2}$.

\section{Conclusions}

High quality rutile single crystals free from low-angle grain boundaries were successfully grown with addition of 1 at $\%$ $\mathrm{Al}_{2} \mathrm{O}_{3}$ and $\mathrm{ZrO}_{2}$ by infrared heating tilting-mirror-type floating zone (TMFZ) method using travelling solvent floating zone (TSFZ) technique. The structural and electronic properties of pure and doped rutile have been analyzed by first principle calculations based on DFT theory using CASTEP code. The calculated structural and electronic parameters are

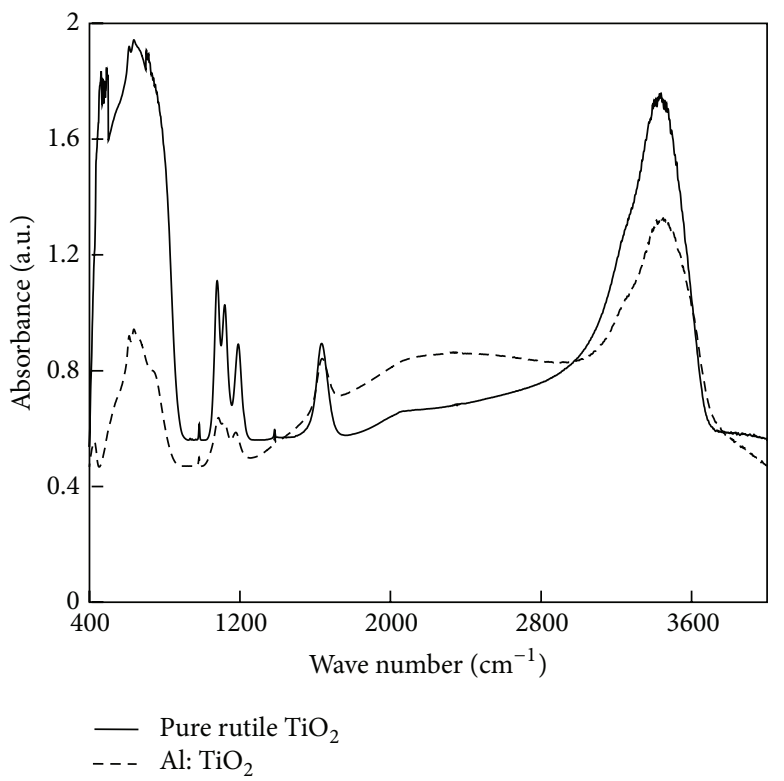

FIGURE 10: FTIR absorption spectra of the (a) pure rutile $\mathrm{TiO}_{2}$ and (b) $\mathrm{Al}: \mathrm{TiO}_{2}$.

in good agreement with experimental values. The ductility of the rutile single crystals decreases slightly for $\mathrm{Al}$ or $\mathrm{Zr}$ doping. The conventional FZ grown rutile crystal contains defects such as dislocations and low-angle grain boundaries. However, Al- or $\mathrm{Zr}$-doped rutile single crystals grown by TMFZ method are free from defects. Therefore, the addition of $\mathrm{Al}$ or $\mathrm{Zr}$ in the rutile $\mathrm{TiO}_{2}$ is the most effective to suppress the defects in order to improve the quality of the grown crystals. The transmission peak of the $\mathrm{Al}: \mathrm{TiO}_{2}$ is far from that of pure rutile. It was revealed that, in case of $\mathrm{Al}$ doping, substitution of two $\mathrm{Ti}^{4+}$ by $\mathrm{Al}^{3+}$ introduces an oxygen vacancy in the rutile $\mathrm{TiO}_{2}$ that would change the color. 


\section{Conflict of Interests}

The author declares that there is no conflict of interests regarding the publication of this paper.

\section{Acknowledgments}

This work was partially supported by the Nippon Sheet Glass Foundation for Materials Science and Engineering, the Sasagawa Science Foundation Program (no. 21-332) of Japan Science Society (JSS), Grant-in-Aid for Scientific Research (C) (no. 20550173) of Japan Society for the Promotion of Science (JSPS), and Rajshahi University Research Grant (no. A 774). The author thanks Mr. Md. Saiful Islam, Senior Scientific Officer, Central Science Laboratory, Rajshahi University, for providing the experimental facilities.

\section{References}

[1] M. Shirasaki and K. Asama, "Compact optical isolator for fibers using birefringent wedges," Applied Optics, vol. 21, no. 23, pp. 4296-4299, 1982.

[2] Y. Nakazumi, "Growth and characterizations of rutile crystals for optical device applications," Seramikkusu, vol. 3, pp. 731-735, 1968 (Japanese).

[3] Y. Nakazumi, K. Suzuki, and T. Yazima, "Observation of etch patterns in $\mathrm{TiO}_{2}$ single crystals," Journal of the Physical Society of Japan, vol. 17, no. 11, p. 1806, 1962.

[4] M. Higuchi and K. Kodaira, "Effect of $\mathrm{ZrO}_{2}$ addition on FZ growth of rutile single crystals," Journal of Crystal Growth, vol. 123, no. 3-4, pp. 495-499, 1992.

[5] R. Wyckoff, Crystal Structures, vol. 1, Interscience, New York, NY, USA, 2nd edition, 1964.

[6] CRC Handbook of Chemistry and Physics, CRC Press, Boca Raton, Fla, USA, 77th edition, 1997.

[7] M. H. Manghnani, E. S. Fisher, and W. S. Brower Jr., "Temperature dependence of the elastic constants of single-crystal rutile between $4^{\circ}$ and $583^{\circ} \mathrm{K}$," Journal of Physics and Chemistry of Solids, vol. 33, no. 11, pp. 2149-2159, 1972.

[8] M. M. Islam, T. Bredow, and A. Gerson, "Electronic properties of oxygen-deficient and aluminum-doped rutile $\mathrm{TiO}_{2}$ from first principles," Physical Review B, vol. 76, Article ID 045217, 9 pages, 2007.

[9] M. A. R. Sarker, S. Watauchi, M. Nagao, T. Watanabe, I. Shindo, and I. Tanaka, "Effects of tilting mirrors on the solidliquid interface during floating zone growth using tilting-mirror-type infrared-heating image furnace," Journal of Crystal Growth, vol. 312, no. 12-13, pp. 2008-2011, 2010.

[10] M. Abdur Razzaque Sarker, S. Watauchi, M. Nagao, T. Watanabe, I. Shindo, and I. Tanaka, "Effects of the diameter of rutile $\left(\mathrm{TiO}_{2}\right)$ single crystals grown using tilting-mirror-type infrared heating image furnace on solidliquid interface and etch pit density," Journal of Crystal Growth, vol. 317, no. 1, pp. 135-138, 2011.

[11] M. A. R. Sarker, S. Watauchi, M. Nagao, T. Watanabe, I. Shindo, and I. Tanaka, "Reduced etch pit density of rutile $\left(\mathrm{TiO}_{2}\right)$ single crystals by growth using a tilting-mirror-type infrared heating image furnace," Crystal Growth and Design, vol. 10, no. 9, pp. 3929-3930, 2010.

[12] D. D. Mulmi, T. Sekiya, N. Kamiya, S. Kurita, Y. Murakami, and T. Kodaira, "Optical and electric properties of Nb-doped anatase $\mathrm{TiO}_{2}$ single crystal," Journal of Physics and Chemistry of Solids, vol. 65, no. 6, pp. 1181-1185, 2004.

[13] M. Higuchi, K. Hatta, J. Takahashi, K. Kodaira, H. Kaneda, and J. Saito, "Floating-zone growth of rutile single crystals inclined at $48^{\circ}$ to the c-axis," Journal of Crystal Growth, vol. 208, no. 1, pp. 501-507, 2000.

[14] S. J. Clark, M. D. Segall, C. J. Pickard et al., "First principles methods using CASTEP," Zeitschrift fur Kristallographie, vol. 220, no. 5-6, pp. 567-571, 2005.

[15] J. P. Perdew, K. Burke, and M. Ernzerhof, "Generalized gradient approximation made simple," Physical Review Letters, vol. 77, no. 18, pp. 3865-3868, 1996.

[16] D. Vanderbilt, "Soft self-consistent pseudopotentials in a generalized eigenvalue formalism," Physical Review B, vol. 41, no. 11, pp. 7892-7895, 1990.

[17] H. J. Monkhorst and J. D. Pack, "Special points for Brillouinzone integrations," Physical Review B, vol. 13, no. 12, pp. 5188$5192,1976$.

[18] T. H. Fisher and J. Almlof, "General methods for geometry and wave function optimization," The Journal of Physical Chemistry, vol. 96, pp. 9768-9774, 1992.

[19] A. Amtout and R. Leonelli, "Optical properties of rutile near its fundamental band gap," Physical Review B, vol. 51, no. 11, pp. 6842-6851, 1995.

[20] T. Mahmood, C. Cao, W. S. Khan, Z. Usman, F. K. Butt, and S. Hussain, "Electronic, elastic, optical properties of rutile $\mathrm{TiO}_{2}$ under pressure: a DFT study," Physica B: Condensed Matter, vol. 407, no. 6, pp. 958-965, 2012.

[21] M. Khan, J. Xu, N. Chen, and W. Cao, "First principle calculations of the electronic and optical properties of pure and (Mo, $\mathrm{N})$ co-doped anatase $\mathrm{TiO}_{2}$," Journal of Alloys and Compounds, vol. 513, pp. 539-545, 2012.

[22] H. Mathieu, J. Pascual, and J. Camassel, "Uniaxial stress dependence of the direct-forbidden and indirect-allowed transitions of TiO2," Physical Review B, vol. 18, no. 12, pp. 6920-6929, 1978.

[23] K. M. Glassford and J. R. Chelikoswsky, "Structural and electronic properties of titanium dioxide," Physical Review B, vol. 46, pp. 1284-1298, 1992.

[24] B. Silvi, N. Fourati, R. Nada, and C. R. A. Catlow, "Pseudopotential periodic hartree-fock study of rutile $\mathrm{TiO}_{2}$," Journal of Physics and Chemistry of Solids, vol. 52, no. 8, pp. 1005-1009, 1991.

[25] J. C. Woicik, E. J. Nelson, L. Kronik et al., "Hybridization and bond-orbital components in site-specific x-ray photoelectron spectra or rutile TiO2," Physical Review Letters, vol. 89, no. 7, Article ID 077401, 4 pages, 2002.

[26] L. D. Finkelstein, E. Z. Kurmaev, M. A. Korotin et al., "Band approach to the excitation-energy dependence of $\mathrm{x}$-ray fluorescence of $\mathrm{TiO}_{2}$," Physical Review B, vol. 60, no. 4, pp. 2212-2217, 1999.

[27] S. G. Park, B. M. Kope, and Y. Nishi, "Electronic correlation effects in reduced rutile $\mathrm{TiO}_{2}$ within the $\mathrm{LDA}+\mathrm{U}$ method," Physical Review B, vol. 82, Article ID 115109, 2010.

[28] W. M. Hirthe and J. O. Brittain, "Dislocations in rutile as revealed by the etch-pit technique," Journal of the American Ceramic Society, vol. 45, pp. 546-554, 2006.

[29] K. Kinoshita and K. Sugii, "Bridgman growth of subgrain boundary free $\mathrm{Pb}_{1-x} \mathrm{Sn}_{x}$ Te single crystals," Journal of Crystal Growth, vol. 71, no. 2, pp. 283-288, 1985. 
[30] K. Hatta, M. Higuchi, J. Takahashi, and K. Kodaira, "Floating zone growth and characterization of aluminum-doped rutile single crystals," Journal of Crystal Growth, vol. 163, no. 3, pp. 279-284, 1996.

[31] W. D. Kingegy, Introduction to Ceramic, John Wiley \& Sons, New York, NY, USA, 1967. 

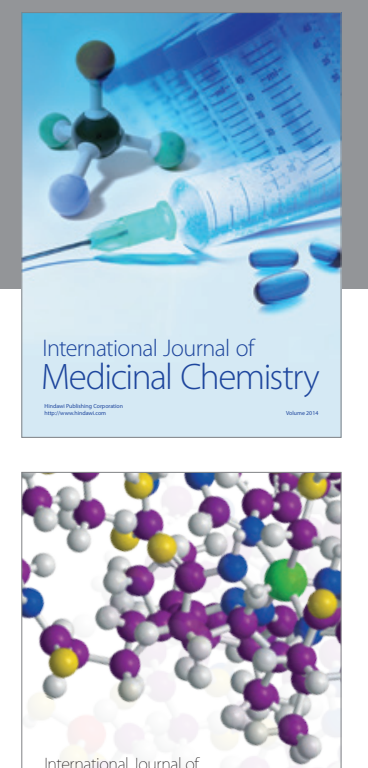

\section{Carbohydrate} Chemistry

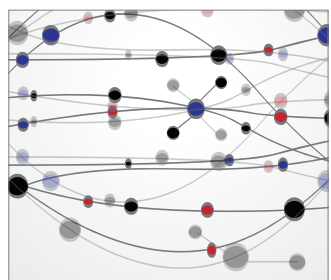

The Scientific World Journal
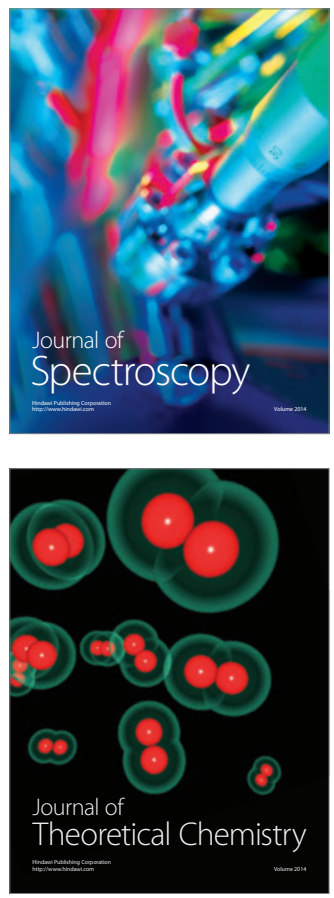
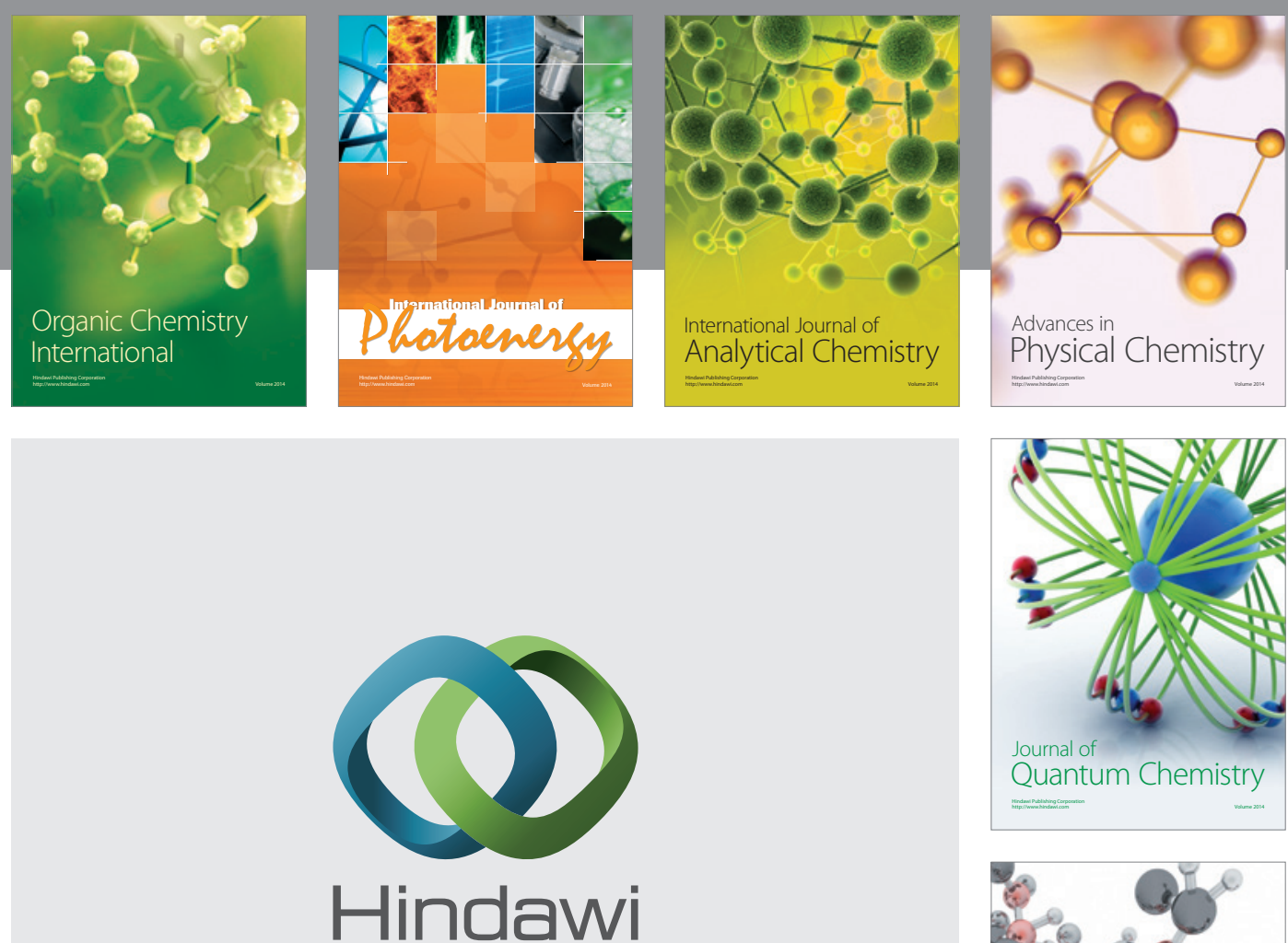

Submit your manuscripts at

http://www.hindawi.com

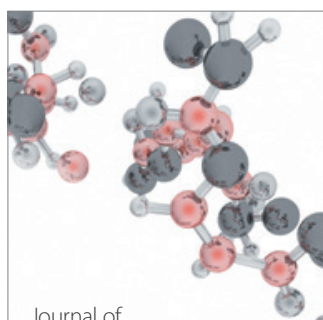

Analytical Methods

in Chemistry

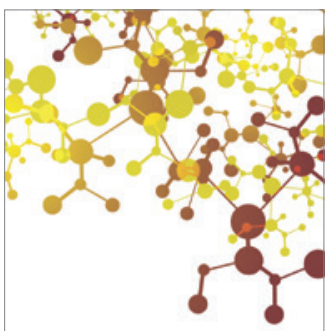

Journal of

Applied Chemistry

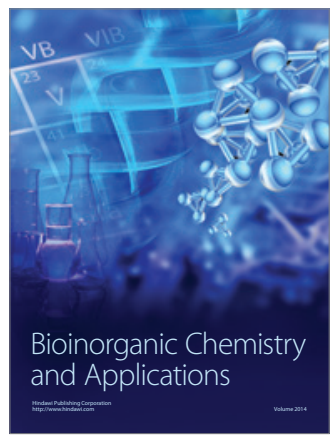

Inorganic Chemistry
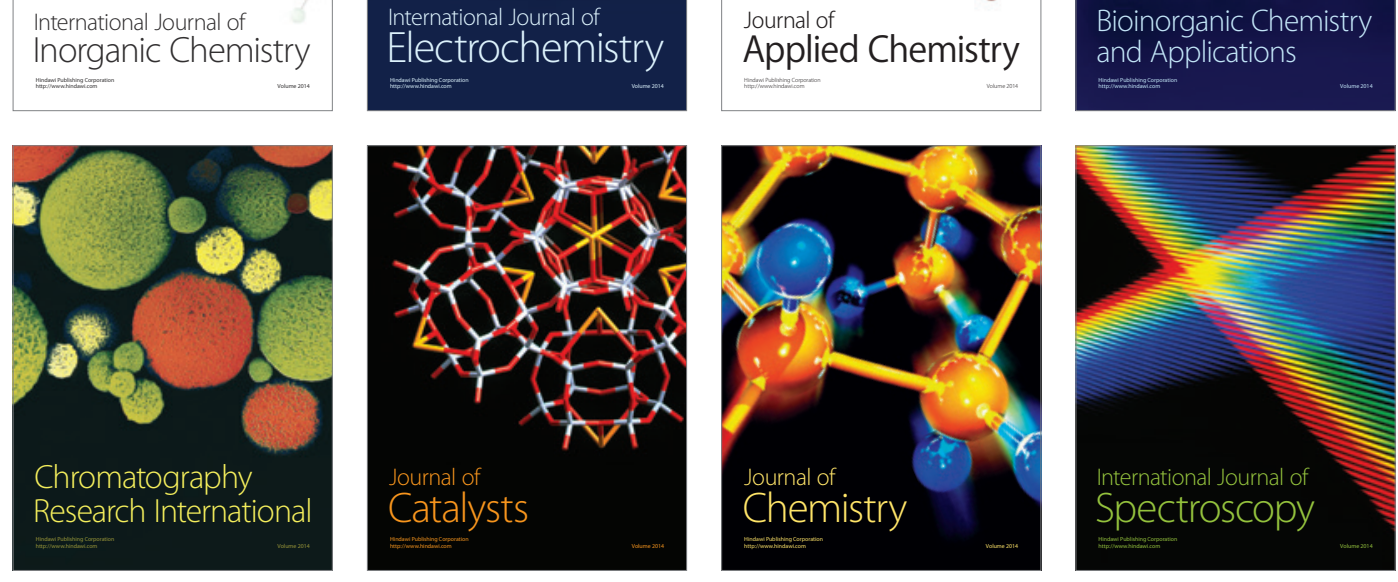